\title{
Topic Study Group No. 16: Teaching and Learning of Calculus
}

\author{
David Bressoud, Victor Martinez-Luaces, Imène Ghedamsi \\ and Günter Törner
}

\begin{abstract}
Aims
This Topic Study Group was a forum for discussions about research and development in the teaching and learning processes of Calculus, both at upper secondary and tertiary level. Invited and oral presentations, as well as posters, showed advances and new trends.
\end{abstract}

\section{Organization}

TSG-16 had four main sessions, four oral communications presentations (two of them divided in two groups) and a general posters meeting. All the contributions were posted on the website of ICME-13.

The accepted papers were organized as follows:

- 6 invited speakers delivered long presentations

- 9 presentations corresponding to extended papers

Co-chairs: David Bressoud, Victor Martinez-Luaces.

Team members: Imène Ghedamsi, Günter Törner.

D. Bressoud ( $\square)$

Macalester College, Saint Paul, USA

e-mail: bressoud@macalester.edu

V. Martinez-Luaces

FJR-Fing, UdelaR, Montevideo, Uruguay

e-mail: victorml@fing.edu.uy

(C) The Author(s) 2017 
- 6 sessions devoted to oral presentations

- 6 posters in one general session

The details are described below.

\section{Main Sessions}

\section{Tuesday, 26 July.}

Session Chair: Imène Ghedamsi.

The invited lecturer David Bressoud (USA) presented a study of university departments of mathematics in the United States, describing efforts being made to improve student success in pre-Calculus and Calculus.

Next, Sarah Mathieu-Soucy (Canada) presented a report on students' perceptions of mathematical theory, suggesting that students see theory as unnecessary for problem solving. She discussed possible remedial strategies.

After that, Young Gon Bae (South Korea-USA) gave an interesting presentation about the flipped classroom as an alternative instructional model. Her team introduced design research for developing a multivariable calculus class.

This first session ended with Günter Törner (Germany) who spoke on the forces that shape the European calculus curriculum and the fractured nature of their influences.

\section{Wednesday, 27 July.}

Session Chair: Günter Törner.

The invited speaker Victor Martinez-Luaces (Uruguay) opened the session; he described some experiences with Calculus inverse modeling problems in teacher training courses in Argentina, Guatemala, Mexico and Uruguay.

Next David Webb (USA) delivered a report on the design and use of instructional tasks for active learning at the undergraduate level.

Yuliya Melnikova (USA) divulged a study on what instructors, teaching assistants, and students consider to be the purpose of the lab component in a Calculus I course. She remarked that there is a need for increased communication to improve classroom practice.

To conclude this session, Mike Thomas (New Zealand) spoke on Integrating Digital Technology in the Teaching and Learning of University Mathematics. His examples focused on the accumulation functions and interval perspectives of functions, particularly the idea of average rate of change.

Friday, 29 July.

Session Chair: Victor Martinez-Luaces.

The invited speaker Imène Ghedamsi (Tunisia) delivered a study conducted on the complexity of the cognitive process by which the formal definition of sequence 
convergence is conceived. This study was framed within the Theory of Didactical Situation (TDS).

Then, Vilma Mesa and colleagues (USA) presented a broad study which observed lessons taught by various instructors at different institutions. After observing and recording the mathematical tasks used in class, she discussed what we learned about calculus teaching.

Jacqueline Coomes and the co-author (USA) gave a talk about the coordination of the symbolic and graphical meanings of function notation. They employed the notions of procept and actor oriented transfer (AOT) to analyze the data and to further explain the issues.

Kevin Moore and his colleague (USA) talked with regard to reasoning about quantities changing in tandem. They described students' ways of thinking for graph and showed the implications in the context of concepts associated with calculus.

\section{Saturday, 30 July.}

Session Chair: David Bressoud.

In the fourth session, a model to analyze the obstacles students have within the transition from calculus to analysis at the entrance to University, was presented by the invited speaker Isabelle Bloch, France.

After that, Claudio Fuentealba and others (Chile-Mexico-Spain) investigated the understanding of the derivative concept in university. The results suggest that the matizing the derivative schema is difficult to achieve.

Tolga Kabaca and colleagues (Turkey) presented research study results that show students' weaknesses in conceptual understanding of integration. In fact, they think that "Integral is a special continuous sum and antiderivative is a genius method to calculate this sum".

\section{Oral Communications}

\section{First Session: Tuesday, 26 July.}

Group A Session Chair Günter Törner.

Sergiy Klymchuck (New Zealand) described his experiences using counterexamples, puzzles and provocations in calculus classes as an effective pedagogical strategy.

Next, Angie Hodge (USA) talked about the use of active or inquiry-based learning (IBL) and how the teaching of undergraduate mathematics course affects pre-service teachers.

After that, Raquel Carneiro (Brazil) investigated which mathematical concepts freshmen students expect for their further studies to detect any gaps in mathematical training.

At the end, Higinio Ramos (Spain) focused on the difficulties that students have with the concept of inverse function, and presented a theorem to obtain indefinite integrals using that concept. 
Group B Session Chair Imène Ghedamsi.

Stefanie Arend (Germany) opened this session and delivered an interesting study centred on the understanding-oriented handling of the epsilon-delta-definition of continuity.

Then, Aggeliki Efstahiou (Greece) presented a teaching sequence focused on building up an alternative definition for the limit of functions of one real variable.

Richard O'Donovan (Switzerland-USA) talked about Calculus using proximities, with an interesting approach in which students can actually prove theorems in a didactical setting.

The last speaker, Analia Berge (Canada), posed a discussion about the transition from Calculus to Analysis, focused on difficulties appearing when systematic theoretical justification is sought.

\section{Second Session: Tuesday, 26 July.}

Group A Session Chair Victor Martinez-Luaces.

Ajit Kumar (India) opened the second session by presenting Sage used as an effective pedagogical tool to teach concepts in Calculus.

Hans-Jürgen Elschenbroich (Germany) proposed the use of technology to create a suitable learning environment for the comprehension of the basic ideas of Calculus.

Next, Matti Pauna (Finland) described the evolution of online Calculus courses. He presented an effective advanced online Calculus course covering definitions and theorems.

Igor Subbotin, (USA-Ukraine) presented an approach of introducing elementary functions via linear algorithms, filling the gap that students find, concerning foundational notions of Calculus.

Lastly, Anna Roos (Germany) talked about a study of the detection of mistakes that undergraduates made. Also, she described the methods used and showed the results obtained.

Group B Session Chair Imène Ghedamsi.

That afternoon, the first speaker Laura Conejo, (Spain) presented an alternative supporting textbook to deal with the concept of limit of a function in mathematics lessons.

Laure Barthel (Israel), taking into account the difficulties encountered by students in Calculus courses, proposed useful material related to the local properties of functions.

Then, Christine Herrera (USA) showed a study on the conceptualizations of limits. Findings indicate that covariational reasoning is fundamental to students' understanding of limits.

The following speaker, Rita Desfitri (Indonesia) delivered a research report focused on analyzing in-service teachers' understanding on the concept of limit and derivative.

After that, Behiye Ubuz (Turkey) presented multilevel models developed to explore how mathematical thinking about derivative varies at the student and classroom levels. 
The last speaker, Marcel Klinger (Germany) reported about a study that assesses students' understanding of the concept of differentiation and the meaning of parameters of a function.

\section{Third Session: Friday, 29 July.}

Session Chair David Bressoud.

The session was opened by Miguel Diaz (Mexico). The presentation documented the understanding process on concepts of Calculus of high school Mexican teachers.

After that, Rebecca Dibbs (USA) presented a course that used post-class reflections to improve students' conceptual understanding of the foundational concepts in calculus.

Monica Panero (France-Italy) shared a study on teachers' practices with the derivative concept and the derivative function. The results show a global perspective on the derivative function.

Finally, Dennis B. Roble (Philippines) talked about a study aimed to determine the levels of students' mathematics comprehension and its impact on their conceptual understanding.

\section{Fourth Session: Friday, 29 July.}

Session Chair David Bressoud.

Marcio Vieria (Brazil) opened the session and reported the results of research whose objective is to develop teaching materials for concepts of Differential and Integral Calculus.

André Henning (Germany) shared a linear approximation approach to high school Calculus. The study remarked that classroom implementation of the developed teaching unit is essential.

Then, Jose Fernandez-Plaza (Spain) studied definitions provided by a group of students of Non-Compulsory Secondary Education about the notion of tendency of a function at a point.

At the end, Mario Caballero-Perez (Mexico) delivered a presentation about the development of variational thinking and language for the teaching and learning of Calculus.

\section{Poster Session}

\section{Tuesday, 26 July.}

In a general session were presented 6 posters of TSG-16. As a key component of communication, the posters allowed the researchers to show a snapshot of their work and interact with colleagues. 
Matias Arce from Spain showed how indeterminate forms are perceived by Grade 11 students. Next, Rongrong Cao (USA-China) presented a Calculus course based on arithmetic. Louis Friedler (USA-China) analysed a China-US calculus study. Then, Xuefen Gao (China) made a comparison of calculus in high school Mathematics textbooks between China and USA. Maria Quezada (Mexico) presented on a Calculus laboratory with free software Desmos. Lastly, Marit Hvalsøe Schou (Denmark) described visualisation in upper secondary Calculus teaching.

\section{Conclusions}

The main themes addressed in TSG-16 were: Calculus teaching and learning, Calculus understanding, transition from secondary to tertiary level, construction of Calculus concepts, learning theories, technology, visualisation, problem-solving, modeling and applications and teacher training courses, among others.

Most of the papers and posters showed interest in innovative approaches to different topics, in order to help students improve their knowledge and comprehension of Calculus. In several cases, these innovations were directly related to the use of technology, whereas in others, they were more involved in the way of thinking, teaching approaches, courses materials, or specific tasks to be carried out by students of different educative levels and university careers.

It is hoped that this interesting interaction between teachers and researchers from different countries, contribute to stimulate creative ideas that make possible continuous headway in the development of mathematics education, particularly, in Calculus teaching and learning.

Open Access Except where otherwise noted, this chapter is licensed under a Creative Commons Attribution 4.0 International License. To view a copy of this license, visit http://creativecommons. org/licenses/by/4.0/.

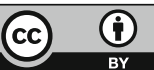

